\title{
The Japanese Restaurant as an Exotic Genre: A Study of Culinary Providers' Practices and Dialogues in Melbourne
}

\author{
Iori Hamada \\ The University of Melbourne
}

\begin{abstract}
This article examines a new mode of 'Japaneseness' emerging through increasing crosscultural exchanges and interactions since the late twentieth century. Based upon ethnographic data and fieldwork, it demonstrates how Japaneseness is reconfigured through contact with other forms such as 'whiteness' within popular commodity culture. Fe article analyses the Japanese restaurant in Melbourne as an 'exotic genre' within which the new mode of Japaneseness is informed and constructed. It argues that this mode of the exotic can be distinguished from earlier formations of exoticism that unproblematically locate a subject monolithically within narrow stereotypes, although the old exoticism has not entirely disappeared. Rather than viewing the Japanese restaurant as a cohesive category, this study conceives of it as a cross-culturally implicated formation that challenges a fixed representation of Japaneseness constructed from a single point of view.
\end{abstract}

\section{Keywords}

Japanese restaurants, Australia, cross-cultural representation, Japaneseness, exoticism

\section{Introduction}

Japanese restaurants outside of Japan are cross-culturally contested sites: they are situated on the boundaries between the inside and the outside, a homeland and a host-land, a subject and an object, as an institutionalised apparatus informing and constructing a particular mode of 'Japaneseness'. Using ethnographic data and fieldwork, I interrogate the conditions of establishments termed as 'Japanese restaurant' outside of Japan, looking at how providers use such a public space to produce images and representations of 'Japaneseness' in a form that is 'exotic'. 'Te exotic, as a particular form of representation, always arises from a specific point of view. I use the term 'exotic' to frame a specific mode of representation that characterises how the Japanese restaurant is formed and how it functions outside Japan.

Similarly, the phrase 'Japanese restaurant' is employed as a represented idea that rests upon a particular point of view. In this article, I do not intend to use only one 
geographic and ideological centre - Japan - to view the Japanese restaurant, nor do I purport that there are authentic representations of the Japanese restaurant by which to judge the particular eating establishments outside of Japan. Rather, my focus here is upon the interrogation into the formation and operation of this institutionalised apparatus in cross-cultural contexts, which requires constant changes in point of view.

Examples in this article are drawn from my in-depth interviews and observations conducted between 2008 and 2011 in Melbourne, Australia. I visited fortytwo restaurants that are registered as 'Japanese restaurants' on the Yellow Pages Local Australian Business Directory Online. ${ }^{1}$ Twenty-seven establishments were selected from the inner city, six establishments from the inner suburbs and nine establishments from the outer suburbs of Melbourne. I conducted semi-structured qualitative interviews with thirty-two providers, including restaurant owners, managers, chefs, wait staff and whole sellers engaged in the local Japanese food industry for varying periods of time. ${ }^{2}$ In this article, I will focus upon two key figures from two Japanese establishments in Melbourne - Keiko, a co-manager of izakaya style dining pub CHIKA, and Kanta, a co-owner of café/shop MARU - to demonstrate how the Japanese restaurant in the Australian context provides a site for the production of a new mode of Japaneseness.

The article is structured into three parts: the first part sets the stage for the theoretical principle of Gilles Deleuze's concept of the fold, demonstrating how it relates to the formation and operation of the Japanese restaurant as an exotic genre. The second part situates the theoretical movement of the fold within the framework of 'whiteness' to examine how the Japanese restaurant 'works' in a 'white' Australia. The last part then provides an analysis of my examples of providers' practices and dialogues, to argue that the fold metaphor allows us to understand a new mode of exotic images and representations that characterise the Japanese restaurant in contemporary Australia.

\section{The Japanese Restaurant as an Exotic Genre}

From take-away sushi shops to newer izakaya style dining pubs, the so-called 'Japanese restaurant' has become almost ubiquitous in metropolitan cities around the world. In Australia's second largest city Melbourne, ${ }^{3}$ there are approximately 120 eating establishments registered as 'Japanese restaurants', according to the Yellow Pages Local

\footnotetext{
1 Telstra Corporation Limited, 'Japanese Restaurants in VIC, Australia', The Yellow Pages Local Australian Business Directory Online.

2 Interviews were conducted in Japanese and in English, and most of them were audio recorded with each informant's permission. The data was transcribed and I translated the Japanese interviews into English. Interviews lasted on average one hour, although several lasted considerably longer (two and a half hours to three hours). Pseudonyms are used in this paper to refer to selected informants and eating establishments. For the scope of this article, I am focusing only upon providers but my doctoral thesis includes consumers' viewpoints to demonstrate the interactive nature of the culinary landscape in Melbourne.

3 According to the 2006 Census, there are 3,592,591 residents in Melbourne; $64.2 \%$ of its population are born in Australia.
} 
Australian Business Directory Online. ${ }^{4}$ Eating out in a Japanese restaurant has become more accessible and desirable in the Australian mainstream market since the late-1990s; it is a popular cultural practice that provides consumers with not only physical, but also socio-cultural pleasures that again feed their desire for cross-cultural exchange.

While there are stereotyped, clichéd exotic images associated with Japanese restaurants (such as waitresses wearing 'kimono', serving 'sukiyaki and playing 'koto' background music), the contemporary formation of the exotic resulting from everincreasing cross-cultural movements seems very different. In cross-cultural contexts, the Japanese restaurant is no longer completely 'foreign', but, as James Clifford writes, is 'the "exotic" [that] is uncannily close. ${ }^{5}$ In contemporary Australia, the Japanese restaurant, as a particular gastronomic and cultural institution, is constructed through increasingly intensified cross-cultural movements that occur within and across different cultural contexts. This mode of the exotic is a product of the collapsed distances of time and space through the processes of globalisation, which enables a more flexible construction of representation.

In this study I suggest that the Japanese restaurant functions as an 'exotic genre': it is located and circumscribed in a category of reception that is marketed, consumed and re-produced as 'Japanese' within exoticism. I use this term to highlight a paradoxical nature of the Japanese restaurant; that is, it 'works' by making itself available to the domestic market, while also by being contained within the exotic genre. The concept of genre manifests itself as its own limit; it is this identificatory construction that can 'permit' difference, and yet in doing so, must contain it within the already identified presence that authorises it. Genre can also, however, challenge a form of identification or fixed categories of identity. Linda Hutcheon suggests that 'classifications of genres are paradoxically built upon the impossibility of firmly defining genre boundaries'. ${ }^{6}$

As an exotic genre, the Japanese restaurant operates on a contradictory structure of representation that is 'inside' (familiar and fashionable) and yet at the same time 'outside' (different and strange). This mode of the exotic exists in the folds between notions of 'inside' and 'outside', thereby suggesting a shift in the relationship between perspectives. This shift can potentially disrupt the fixity of these categories, which can be described using a particular metaphor: the fold.

Telstra Corporation Limited, 'Japanese Restaurants in VIC, Australia', The Yellow Pages Local Australian Business Directory Online.

Clifford, The Predicament of Culture, p. 13.

Hutcheon, The Canadian Postmodern: A Study of Contemporary English-Canadian Fiction, 1988, p. 22. 


\section{The Fold: From Essence To Sensed}

In 'The Fold: Leibniz and the Baroque', Gilles Deleuze describes a system of complex interactions between the inside and the outside through the metaphor of the fold. Deleuze suggests, deploying Leibniz's monadic theory, that there are constant shifts in perspectives or positionalities. Leibniz's notion of monads, or discrete entities of knowable existence, describes the world as an infinite series of folds. As a perspective, each monad corresponds to one way of seeing the world, whereby the movement of the fold operates as a representational series. The fold produces a separation and a connection, as it unfolds and re-folds. It marks a boundary on a piece of fabric or a sheet of paper while bringing both sides of the divide together. In 'The Fold', Deleuze utilises the Baroque not to refer to a particular historical period, but to characterise it as an 'operative function' that disrupts presumed dichotomies of understanding, such as a phenomenon's 'appearance' and its 'essence.' The model of the 'Baroque House' has two levels, according to 'the pleats of matter' and 'the folds in the soul.' ${ }^{8}$ The lower level is opened to the outside world through windows, which represent the five senses. The upper level is a closed, private room, referring to the inner self, or the soul. These two floors are not, however, disconnected; they are 'one and the same world', connecting through the folds that are 'virtual', although potentially actualised in the soul and realised in matter. ${ }^{9}$ It is important to note that Deleuze's notion of the virtual is not the same as virtual reality. Whereas virtual reality is thought of colloquially as an idea of imitating reality and reproducing its experience in an artificial medium, the virtual in this case refers to the reality of the virtual; that is, it has 'real' effects, and therefore it is immanent in the actual. ${ }^{10}$ Thus, the virtual entails an unfolding that moves the exotic from an inside view into an outside, whereby the distinction between them becomes no longer clear.

The fold metaphor is useful because we can see how the Japanese restaurant is formed and operates as an exotic genre, which is produced through constant movements between the inside and the outside. In the contemporary Australian context, the Japanese restaurant 'works' through the acts of connecting and separating: it can be connected to the mainstream market, while maintaining itself as separate, producing paradoxical effects that are both 'close' and 'different'. Through this two-way movement, the Japanese restaurant becomes intelligible, that is, it 'makes sense' to the dominant clientele, yet at the same time it also functions as a site of 'difference', which can contest authenticity and potentially dislocate fixed categories of identity. The trope of the fold

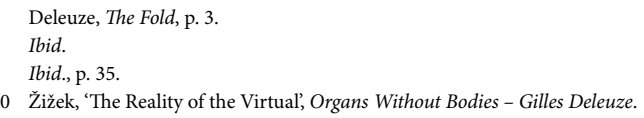


has the ability to follow a constant shift from object to subject positions as it moves. This flexible movement allows us to find an alternative way to see the Japanese restaurant that can be sensed through bodily experience, rather than being essentialised. It is important to note, however, that the fold is not a free-flowing movement, but rather a dialectical narrative that enables communication between different categories. This containment inherent in the movement of the fold relates to the Japanese restaurant in the Australian context, since while there is de-contextualisation and re-contextualisation in the cross-cultural construction, the Japanese restaurant also always refers to that which is 'Japanese' within the exotic genre.

Using my examples, I aim to demonstrate how the Japanese restaurant provides a site for the production and consumption of Japaneseness within popular commodity culture. The fold metaphor is employed to make visible the constructedness of Japaneseness that is enabled by specific social interactions and institutions that produce the particular representational form. Through the concept of the fold, it also describes how there is a fold between the inside and the outside, the virtual and the actual, and the soul and the body, in the formation and operation of the Japanese restaurant, and how providers attempt to make sense between these categories in the Australian context. What I am suggesting is, then, a conceptual movement from essence, to representation and embodiment, through which to see an alternative mode of the exotic.

\section{The Japanese Restaurant in a 'White' Australia}

To understand how the Japanese restaurant functions overseas requires an examination of a specific context where it is placed. Due to the relatively small size of the Japaneseborn residents in Melbourne, ${ }^{11}$ most of the clientele of local Japanese restaurants are from different cultural and ethnic groups; dominantly from the Anglo-European Australian population, although clientele from Asian-Australian groups are also playing an increasingly important role in the industry. This ethno-demographic condition, which also informs the domestic mainstream market, has impacted how the providers structure their practices within the exotic genre. In other words, the formation and operation of the Japanese restaurant is dependent upon the dominant clientele's expectations and recognitions (or misrecognitions) of what 'Japanese restaurant' is or should be. In my interviews, this was indicated when many of the providers identified their clientele as 'dominantly white Australians', and remarked that they customised

11 The number of Japanese-born residents in Melbourne is 5,287, according to the 2006 Census. The Japanese-born residents indicate people of Japanese ancestry who are resident in Australia, whether through birth or immigration. The 2006 Census excludes Australian-born persons of Japanese ancestry, and Japanese in Australia as overseas visitors (and would include non-Japanese born in Japan). By comparison, the 2006 Census shows that the Chinese population is 182,550; these are residents who identified themselves as having Chinese ancestry (either exclusively or with another ancestry). 
their products and service according to the specific groups of clientele. A Japanese-born owner/head chef of an up-market restaurant in the central business district (CBD), one of my informants, commented that:

Our business would never work here if we only set to target Japanese customers, who are definitely not many. ... Certainly we are designing our business around the needs from our clientele, who are dominantly white Australians [hakujin no osutoraria jin]. So we make sure that their demands are met in terms of what kind of taste they prefer and what types of Japanese dishes they know and like. So we do have things like teriyaki and yakiniku that are easily recognisable to those people, while we also have homemade soba, which is probably a not so commonly known Japanese dish in Melbourne.

It is necessary to point out that while this ethno-demographic condition constructs whom the providers recognise as the dominant clientele, their recognition does not necessarily reflect the dominant clientele exactly, and instead constitutes a 'stereotype' to whom they conform. I would suggest that this stereotype is about expectations, both on the part of providers and their perceived notion of the consumers' desire, which is also informed by the socio-cultural reality.

In examining how providers act in response to their clientele's demands and perpetuated ideas as to what the clientele expect from the Japanese restaurant, Ghassan Hage's arguments on the white nation fantasy become instructive. Hage suggests that Australia is ideologically and legally built upon a 'white' centre: it is a 'white nation' fantasy that sustains, and is framed through, the popular conception of Australia as a white settler nation. ${ }^{12}$ Here, it is important to emphasise that whiteness is not a fixed racial category ascribed to particular skin colours and geographic origins; but rather, as Hage suggests, it is an accumulated position that can be taken up within the national (white) discourses. ${ }^{13}$ As addressed earlier, the Japanese restaurant gains entry into, and success in, the domestic dominant (white) market through the acts of connecting and separating. It is this paradoxical structure of the Japanese restaurant - which is both inside and outside of the dominant socio-cultural 'norm' - that can deal with consumers' anxiety about, as well as their fascination with, the outside or the 'foreign'. I employ the phrase 'domestic dominant (white) market' to refer specifically to the white dominance that ideologically and empirically contains, and thus sanctions, particular kinds of others within the national space. 


\section{Cosmo-multicultural Consumption: How Do White Australians 'Experience' Multiculturalism?}

In further interrogating how this imaginary national space has impacted the conditions of the Japanese restaurant in the Australian context, this section looks at a particular mode of consumption practices that the Japanese restaurant provides a site for. Following Ghassan Hage's notion of white multiculturalism, I argue that the Japanese restaurant becomes commodified specifically for the domestic dominant (white) market, whereby (white) Australians can consume and experience Otherness within the national space. This mode of consumption will be also referred to as a form of cosmopolitanism, while locating the Japanese restaurant within the everyday spaces, where multiculturalism is in place.

Multiculturalism in Australia was adopted by the Whitlam Labour government in 1973 after the rescinding of the White Australia Policy. It is therefore a state-run, 'top-down' political strategy, structurally dissimilar to multiculturalism practiced in America that is a minority-initiated, 'bottom-up' policy, against the US government's ideology of the country as a 'melting pot.' ${ }^{14}$ Hage argues that multiculturalism in Australia is also a white national fantasy: white multiculturalism allows some white Australians to manage 'cultural diversity' through sanctioning the 'Other', and their fears over it. ${ }^{15}$ Multiculturalism as 'cultural diversity' uses non-white ethnicities as a way of valorising a white centre, while at the same time superficially valuing 'cultural diversity' where non-white ethnic subjects are involved. Hage suggests that current debates on multiculturalism highlight this point, since their focus is more upon how white Australians experience multiculturalism, rather than what multiculturalism is or is not. ${ }^{16}$ In other words, Australia's form of multiculturalism centres on reinforcing whiteness, not other ethnicities, whereby white Australians can experience 'cultural diversity' as part of their own 'cultural enrichment'.

As a multicultural theme, 'cultural enrichment' relates to cosmopolitan consumption, which is predicated upon an interest in other cultures. This mode of consumption emphasises not merely commodities per se but also consumption experience, whereby consumers are touched through the senses. Cosmopolitan consumption is also a classed practice, as it exposes consumers' cultural (and often socio-economic) capacities to appreciate commodities that cannot be necessarily intelligible within their own coding systems. In interrogating the link between multiculturalism in Australian contexts and cosmopolitan consumption, the term

14 Stratton and Ang, 'Multicultural Imagined Communities', p. 126.

15 Hage, White Nation, p. 119.

16 Ibid., p. 18. 
'cosmo-multiculturalism', borrowed from Hage, becomes useful. Hage characterises Australia's multiculturalism as 'cosmopolite', referring to the 1988 Fitzgerald Inquiry report where the term cosmopolitanism was utilised to signify multiculturalism. He posits that 'the cosmopolite is a class figure and a White person, capable of appreciating and consuming "high-quality" commodities and cultures, including "ethnic" culture. ${ }^{17}$ While it is important to highlight that cosmopolitanism is not necessarily a white privilege, Hage's argument is suggestive in a way that shows how cosmopolitanism has become a mode of conceiving multiculturalism in Australia, and how this can enable a shift between 'white' and 'non-white', and subject and object status.

The term cosmo-multiculturalism is relevant to the context of the Japanese restaurant in Melbourne when looking at how it is consumed and experienced within the dominant (white) market. Dining out in a Japanese restaurant in an Australian metropolitan city is linked to 'taste' - not only taste as a sensation, but also taste as an aesthetics that corresponds to particular consumption practices assigned as 'highclass. ${ }^{\prime 1}$ It is a classed experience, as well as a popular cultural one, since it is often only available to those with the resources to consume and appreciate what is provided in the site. ${ }^{19}$ This mode of consumption practices can be thus thought of as 'cosmomulticultural' in that the Japanese restaurant is located within popular culture as a sign of cosmopolitanism.

Similarly the term is useful because it can describe a new mode of the exotic that is marketed specifically for (white) Australians, while also maintaining it as 'different' and 'novel'. Although there are issues of commodification and fetishisation surrounding the consumption practices, the frame of cosmo-multiculturalism allows us to see how the Japanese restaurant is being used to 'update' the domestic food spaces, as forming part of (white) Australia. What I am suggesting is a representational shift occurring within commodity culture since the late-1990s: no longer seen merely as 'quaint' and 'foreign', the Japanese restaurant is now perceived as 'high-class' and 'fashionable', thereby becoming marketable today for the new images in (white) Australia. ${ }^{20}$ It is this new mode of the exotic that is unfolded into the domestic dominant (white) market, while being

17 Ibid., p. 201 (original emphasis).

18 Bourdieu, Distinction, p. 99.

19 In my interviews with consumers, dining out in local Japanese restaurants was often described as an 'elitist' practice. An Anglo-European Australian social worker in her fifties, for example, characterised the Japanese restaurant as 'an elitist place'. She explained:

[Japanese restaurants] tend to focus more on quality rather than quantity. It is also relatively expensive so when I eat out I expect the place to provide an authentic dining experience. So it's a bit like elitism, you know. If you dine out at a Japanese restaurant, you would like to have high quality food and service and all that. I have been to a Japanese shop down the road run by probably Chinese, you know, you can kind of tell whether they are Japanese or not, but they just at most put a few lanterns and are very limited in presentation of Japanese aesthetics. Because that's the only Japanese place around here. We have a kind of perception that Japanese products are high quality whereas products made in China are usually not that good. As her comments suggest, dining out in the Japanese restaurant in contemporary Australia works to produce a sign of cosmopolitanism, closely tied to aesthetic taste and class.

20 Although their research site is Los Angeles, America, ethnographic studies conducted by Ishige et al. provide a useful analysis of how the Japanese restaurant outside of Japan was previously represented within exoticism. See Ishige et al., Rosuanjerusu no Nihon Ryōriten. 
still contained as that which is different. What enables this, I argue, is the providers' self-conscious insertion of other forms such as 'whiteness' into the exotic, which will be demonstrated through an analysis of my examples in the following sections.

\section{The Izakaya: Folding 'Whiteness' Into a New Exotic}

The izakaya, as a newly emergent public dining space, exemplifies how the exotic genre of the Japanese restaurant unfolds into the popular national food spaces, while still being constrained by the very genre. As author of Izakaya Mark Robinson observes, 'the izakaya is overdue to become one of the biggest Japanese cuisine trends abroad since the sushi bar. ${ }^{21}$ This traditional Japanese dining style, which evolved from casual eateries, or niuriya, ${ }^{22}$ in the Edo period (1603-1867), is now appearing as a new exotic in international urban gastronomic scenes, from New York, to London and Melbourne.

In her column 'Espresso', Melbourne's leading newspaper The Age's chief restaurant reviewer Larissa Dubecki wrote that 'until recently the notion of the izakaya was pretty much exclusively known to Japanophiles. Now, it's a mini-trend taking Melbourne by storm ....23 Within the last five years, at least eight izakaya-influenced establishments have opened up, spread throughout the city and inner suburbs of Melbourne. Owner of three izakaya-inspired dining pubs including Melbourne's oldest izakaya eatery opened in 1989, Chris thinks that the izakaya is an effective business model because it is still generally seen as 'novel', yet not completely 'foreign' for local consumers in Melbourne. This Anglo-European Australian entrepreneur in his thirties, who has been preoccupied with Japanese cultures from anime to $s a k e,{ }^{24}$ commented that:

Japanese izakaya style cuisine is a very accessible style of dining. It's like Spanish tapas, you know. You can eat lots of small things and you can share and, ah, it's very communal. ... Niche market, but I think it's getting bigger. Four or five izakaya style restaurants opened up rapidly over the last year or two [in Melbourne]. Definitely it's getting popular.

The izakaya 'works' because it can produce 'familiarity' as an exotic effect. As Chris observes, there are some aspects in the newly emerged dining style that allow a connection to the dominant (white) market. The sharing of small dishes is one such

\footnotetext{
21 Robinson, Izakaya, p. 6.

22 Ibid., p. 48-9. Robinson explains that niuriya (煮売り屋) 'sold simmered food in broth, then later sashimi, tempura and other fish and vegetable dishes (meat being against Buddhist percepts)'.

23 Dubecki, 'Espresso, The Age Online.

24 Chris took Level 1 and 2 Sake Professional Courses sponsored by the Sake Education between 2007 and 2008. He also regularly visits a number of sake breweries in Japan to broaden his knowledge in Japanese sake and shöchu.
} 
aspect, as it is also characteristic of already existing parts of the local gastronomic scene; namely, Mediterranean cuisines. ${ }^{25}$ It is this whiteness that is foregrounded through the act of connecting so that the izakaya 'makes sense' to Melbourne's mainstream customer. A wide selection of locally produced wines is also another 'white' aspect that many of the local izakaya-influenced establishments use to produce familiarity, as well as novelty and surprise. Of the newest izakaya-influenced places CHIKA, for example, features a collection of wines that is all-Victorian, aligned with imported sake, shōchu, umeshu and Japanese beers on their two-page drink list, producing a cosmopolitan fold - that is, 'in' and 'out' - between different localities. The insertion of whiteness into the new exotic is, however, not just a simple hybridity. Whiteness reconfigures (if not being reconfigured by) the Japanese restaurant, in tension against, and in conjunction with, that which is different. Focusing upon the story of Keiko, a co-manager of CHIKA, the next section further examines how the movement of the fold can describe the formation and operation of the Japanese restaurant within the domestic dominant (white) market, and how providers strategically incorporate whiteness into Japaneseness to produce a new mode of the exotic.

\section{Keiko from CHIKA: Sensing the Exotic, Making Sense of the Logic of the Izakaya}

Keiko, a Japanese-born woman in her forties, migrated to Australia in 1983. When she first arrived in Melbourne, Keiko started off working part-time as a waitress in a traditional teppanyaki restaurant in the CBD. In my interview, she recalled that working at a Japanese restaurant back then was merely for sustaining her study at university and art practice. Despite her initial intention to keep pursuing her art practice in the new destination, Keiko ended up staying in the local Japanese restaurant industry, expanding her professional horizon from being a casual wait staff to being a restaurant manager over the past twenty years. After working in Melbourne's oldest existent Japanese establishment, where traditional Japanese foods such as sushi and tempura are served in a modern, relatively formal atmosphere, Keiko decided to set up a new dining space in the city with her business partners; Adrian, an Anglo-European Australian restaurateur, and Tetsu, the Japanese-born former manager of Adrian's high-end Japanese-influenced European restaurant SPIRAL. With them, Keiko developed her business ideas and ultimately opened an urbane izakaya dining pub CHIKA on a main street in the CBD in 2009. In the interview, she described:

It was something we had been working on for five or six years. Adrian and I started discussing new restaurant plans, and then Tetsu came in because he

25 Mallos, 'Mediterranean Influences', pp. 16-18. 
was working in Adrian's restaurant at that time. ... There were a couple of hiccups on and off on its way, but we kept pushing it and trying to make it happen. ... We were pretty clear on what we wanted to do, something that is Japanese, but definitely contemporary one, um, something that is yet to be seen in Melbourne.

Keiko's reasons to initiate the project lie in her desire to update the old images that have been used to represent the Japanese restaurant in Melbourne. Keiko said:

After all, anywhere you go in Melbourne, you'll find a traditional Japan [toradishonaru na nihon]. That's fine, but we also need something new, something that can show what's really happening in contemporary Japan. [Food culture in] Japan has gone further, but restaurants here do not seem to be keeping up with it. So we kind of felt that it's time to show people a newer Japan [motto atarashii nihon]. We've had enough sushi and teriyaki chicken here so we decided to do something different to what they usually think is Japanese food.

Rather than repeating clichéd images (such as, 'sushi and teriyaki chicken') circulating in the popular commodity culture, Keiko's desire is to produce new images that reflect the presentness of Japan's food culture, bringing a break into the tradition that places the Japanese restaurant outside time - perpetually 'present'. In this sense, CHIKA can be understood as a site for Keiko to re-represent the Japanese restaurant with time, and therefore contemporary.

In addition to her continuous dialogues with her business partners, what made this desire 'realised' in the matter was a book; Mark Robinson's Izakaya. Keiko explained:

Then, we came across a book called 'Izakaya' written by an Australian guy living in Tokyo. The book was quite inspirational to develop our ideas about what kind of Japanese restaurant we wanted to do and could work here [in Melbourne]. The book is about different types of izakaya in Tokyo, all of which have their own styles. It's a great book. It shows some photos of the actual spaces, the history of each izakaya and also some of their recipes that they're actually using in the sites.

In fact, we made trips to Tokyo to visit those places featured in the book and see what they're like. The trips were a bit crazy. Since our time was limited, we hopped from one izakaya to another each night and tried different foods and drinks, talked to people there and got some recommendations from them as to what to check out. But it was great fun because we got a lot of ideas from the trips, which became really useful when we designed the architecture, the interior, the menu and so on. 
Robinson's book thus has 'real' effects that allowed them to actually visit the izakaya places featured in the book, physically experience what they're providing and ultimately materialise their ideas into their own izakaya. It is this movement, I suggest, that characterises the formation of CHIKA through which to fold between 'virtual' and 'actual' spaces - from the virtual (book) space, to the actual izakaya spaces in Tokyo and the everyday food space in Melbourne.

The movement of the fold also has the ability to describe the operations of CHIKA within the domestic dominant (white) market. As addressed earlier, the Japanese restaurant in the Australian context functions as an exotic genre, since it is separated as that which is 'different' while being unfolded into the Australian national framework. This paradoxical structure characterising the Japanese restaurant is pertinent to the operations of CHIKA, where both 'closeness' and 'difference' is produced as effects of the exotic.

Designed by a renowned Melbourne architecture firm run by Adrian's father, this new izakaya creates an atmosphere of urban cool, strategically incorporating whiteness into Japaneseness. Its industrial minimalist aesthetic is manifested through concrete walls, the building's metal beams running through the ceiling and marbletopped tables reflected on an about three meter-high mirror placed at the end of the tunnel-like basement space. Male and female staff wearing black uniforms, red sneakers and colourful headscarves, most of who are Japanese-born in their twenties and thirties, are busily yet quietly attending to their middle to upper class clients, to the beat of a soundtrack such as soul, reggae and rock music. Their regular dinner menu comes in a washi paper scroll listing small dishes of foods and drinks ranging from imported Japanese sake to locally grown wines, in both English and Japanese. Their behind-thebar open kitchen functions as a central pit, producing elaborately presented small dishes, such as deep-fried sweet corn fritters with a pinch of green tea sea salt, small rectangular pieces of wagyu tataki served with soy sauce dressing and wasabi mayonnaise, and salted grilled kingfish heads. To meet the demands for vegetarian options, they also have relatively diverse choices of vegetarian dishes, such as lightly steamed crunchy seasonal vegetables with a dipping sauce made from a yuzu citrus chilli koshō spice and sour cream, and sesame stir-fried Japanese eringi mushrooms.

CHIKA translates the izakaya, which is conventionally a cheap, casual drinking place, into something chic and high-class, closely tied to aesthetic taste and class. Their relatively high-priced foods (from AU $\$ 5$ to AU $\$ 33$ per dish) and drinks (from AU $\$ 25$ for a $400 \mathrm{ml}$ bottle to $A U \$ 220$ for a $720 \mathrm{ml}$ of the most premium) can suggest that they strategically limit their clientele to socially and economically privileged groups who are able to consume and appreciate other cultures. Not only is dining out in CHIKA a cultural experience, but also a classed one, thereby producing a sign of cosmopolitan consumption. 
What the consumers can gain in exchange for the prices are, then, cosmopolitan pleasures, with which the other can be sensed, rather than being simply objectified, through bodily experience. To make this cosmopolitan consumption possible, CHIKA folds whiteness, which is represented through the local markers (such as, the wines and the architecture), into Japaneseness as a way of making sense of the other.

While the fold into whiteness works to connect CHIKA to the dominant domestic (white) market, there is also a separation, through which CHIKA can differentiate it from other places. Their use of a 'different' logic within the site most explicitly illustrates this. In the interview, Keiko said that 'there is a logic ['rojikku'] of the izakaya, a way to experience and understand this form of dining. Highlighting 'sharing dishes' and 'repeating orders' as the underpinning elements of the logic, she described how CHIKA operates to maintain 'difference' within the dominant (white) market:

When it comes to dining style, people here [in Melbourne] still have, ah, sort of like, an entrée-first-then-main mindset. But the izakaya doesn't work like that. At izakaya, you share dishes.... You order three or four dishes at a time, and then repeat it until you've had enough.

As Mark Robinson illustrates, within the logic of the izakaya customers are expected to 'order small-dish delicacies throughout the evening, perhaps in the beginning sharing just a couple of items. The menu is like a road map and the diners are at the wheel, calling out orders as the mood takes them.'. ${ }^{26}$ Whereas course meals set temporal and spatial grids that allocate an individual diner in a fixed location, the 'tablescape' of the izakaya can become messy, as foods, drinks, utensils and other elements constituting the space constantly cross over between physical and symbolic boundaries through sharing. This tablescape also works in tandem with the acts of ordering. The izakaya is structured through a 'play' mode with a repeat option (albeit different each time), rather than through a set course to follow: it is in the course of 'events' that human agency can spontaneously act and react, thereby enabling a move from essence, to representation and embodiment.

As a 'different' logic, the izakaya dining system, which operates at CHIKA, can be 'foreign' to the dominant (white) clientele. Keiko described that:

People here ['kocchino hito'] sometimes don't get it. I'm like, 'Guys, you don't need to order everything in the first place.' But they do. That's what they usually do. When they get the table they order and that's it. After that, they put the

26 Robinson, Izakaya, p. 8. 
menu aside and forget about it until we come to take it away. But, that kind of logic doesn't work in izakaya. ... So I let them order whatever they want, but then I tell them that 'I'll bring this and this first so see how it goes'.

How she described that the 'different' logic may not make sense to the clientele suggests not only the limitations of their own, but also the potential for a shift from object to subject status, since the logic can become subjectified through the senses. In Keiko's comments, this is illustrative when she used the word 'kankaku', which loosely translates as 'feeling' or 'sense(s)', to explain how making sense of the logic of the izakaya requires the body to sense it. She said:

In izakaya, you eat, drink, share, communicate ['komyunikeito shinagara'] and have a good time. So there are a lot of different things that can happen at the same time [in izakaya], but this kind of feeling ['kankaku'] is what makes an izakaya really an izakaya, I guess. That's very much how the izakaya works. So I've found it quite different to what people would usually expect from Japanese restaurants here [in Melbourne], but this kind of feeling ['kankaku'] is really, ah, the core essence of the izakaya that we're kind of trying to get across.

In her comments, the word 'kankaku' refers to a necessary basis for understanding a supposed essence - 'what makes an izakaya really an izakaya'. However, the essence expressed by the word 'kankaku' is not necessarily rendered as a fixed site; but rather, it is flexible enough that it can be embodied through the senses, thereby blurring the distinction between object and subject. This is the new mode of the exotic that I have argued through the fold metaphor; the exotic that collapses between the essence and the senses, and therefore enables shifts from essence, to representation and embodiment.

\section{Kanta From MARU: 'From Head To Hands and Heart'}

Along with the current izakaya boom, there is another new type of Japanese establishment appearing in the local food spaces: 'soul food' cafés. Café/shop MARU run by a Japanese-born couple Kanta and Tamaki is a new addition to the long-established café culture, ${ }^{27}$ as well as the Japanese restaurant industry, in Melbourne. They interpret those seemingly separated types of eating establishments in a way that produces new images of Japaneseness. Since opening its doors in a laid-back inner suburb in Western Melbourne in 2008, MARU has offered the local clients a new outlook of contemporary Japan. Veering away from popular images associated with modern Japan (Japan the

$\overline{27}$ See Frost, Laing, Wheeler, and Reeves, 'Coffee Culture, Heritage and Destination Image: Melbourne and the Italian Model', pp. 99-110. 
'rapid', the 'high-tech' and the 'consumerist'), Kanta and Tamaki re-present a slower, handcrafted and post-consumerist Japan through their aesthetic expression of a 'less-ismore' lifestyle. In my interview, Kanta said:

This place is about reflecting elements of what we love and what we care about. There are three concepts that are especially valued in this space, which are 'style, 'food' and 'living. We understand each concept in relation to our body and soul, using key words like 'head', 'hands' and 'heart', to suggest a happy life that we think needs all of these. That is, using not only your head but also your hands and heart makes it possible to feel, touch and treasure beautiful, little things in your everyday life.

The café owner, who is also an architect originally from Tokyo, transformed a warehouse into the café/shop space that caters to the local residents and workers who are dominantly Anglo-European Australian. This refurbished warehouse located in a backstreet operates two parts as one, folding whiteness into Japaneseness. The front part is the café dining area, where four members of the MARU team, comprising Kanta, Tamaki, another Japanese-born chef and an Anglo-Australian male waiter perhaps in their twenties and thirties, are moving in and out of the open kitchen, dividing (or connecting) the whole space. Different styles of furniture - new, old, wooden, metal and plastic tables and chairs - were sourced from a combination of second hand stores and a contact in Denmark, crossing over between different time-space boundaries. Instead of sushi and tempura, MARU serves Japanese karē raisu (curry with rice) and cold soba noodle salad and other simple, unpretentious, everyday Japanese dishes, along with Western basics such as sandwiches, albeit through their own interpretation. On Saturday mornings they provide a Japanese home-style breakfast plate, consisting of Tamaki's grandmother's style miso soup, brown rice, tamagoyaki egg rolls, potato salad, cold ohitashi steamed spinach, grilled salmon, and if requested, maccha muffins with red bean azuki paste inside. The other part at the back is a shop, featuring handcrafted Japanese products, such as tenugui cotton towels, ceramics, lacquer-ware, drinking glasses, recycled paper tote bags and toy robots, decorated with pieces of Danish designer furniture.

Although it is added to the local café culture, MARU does not seem to be completely added up to it; but rather, it functions as an exotic site, producing effects that are both 'fashionable' and 'different'. Their home-style Japanese breakfast and carefully selected Japanese handcrafted domestic items particularly indicate this, as their 'everydayness' and 'domesticity' is encountered anew in the contemporary Australian context through translation and displacement. It is notable, however, that their exoticising of the space is not the same as a self-Orientalising process, which is intended 
to reverse self-other positions or insist other's uniqueness. Instead, MARU refers to the self that has already taken the influence of the 'West' other, thereby suggesting shifts in perspectives and the production of subjectivity. Furthermore, the whiteness constituting the space is not a single, unified identity; rather, they compose different white identities (such as, the local white consumers, the white waiter, the furniture from Denmark and the Japanese style Western yōshoku food) through their strategic use of aesthetics, predicated upon the 'less-is-more' lifestyle. In this sense, at MARU, whiteness functions neither to supplement Japaneseness nor to reverse exoticism (that is, whiteness exoticised by non-whiteness); but rather, it serves as a site to re-work Japaneseness through a discursive exchange of meaning.

To make sense of this new mode of the exotic, MARU deploys materials as a medium, as well as a subject, in their representation; food and other cultural products function to represent a particular life style that values a 'less-is-more' mentality, with which they associate slower, handcrafted and post-consumerist images of Japan. Aesthetics also play an integral part in this meaning making process, since it produces sensory effects and thus can enable a move between representation and embodiment. It is also worth mentioning that MARU's utilisation of aesthetics does not let form (that is, how Japan looks) be placed over content (that is, a Japanese lifestyle); but rather, form (the outside) works as a necessary part of content (the inside) that it contains. In the interview, Kanta said that:

\begin{abstract}
All of the products are selected because of their quality. They can endure the demands of everyday use. So it's not just about aesthetics, but it's also about practicality and how they can make our everyday life more enjoyable and sophisticated.
\end{abstract}

While the comments imply their attempts to produce a certain identity or 'interiority' for Japaneseness through the display of these traditionally made Japanese domestic products, their practices do not necessarily hierarchise the categories of content and form; instead, they fold between them, again allowing a shift from essence, to representation and embodiment.

This conceptual movement can also describe their formation of Japaneseness through which to represent an immediate experience of a Japanese lifestyle that at the same time others in the dominant domestic (white) market. Kanta's following comments demonstrate how the perception and consumption of the new mode of the exotic requires the operation of all the senses, thereby possibly disrupting the fixity of subject and object positions. He said: 
Instead of presenting just one aspect of Japanese culture, we wanted to show different elements that can express a certain life style that we value. So we designed our café in a way that people can sense that, and, if they like, they can even take some home and enjoy them through materials in their own life space.

The comments suggest that consumption practices unfold (or expand) the popularity of the exotic into the outside of the site. In this regard, MARU operates as an informed site through which to produce the new mode of the exotic that can touch the consumers and thus create potential empowerment, or agency, in their representation.

\section{Conclusion}

My attempts to see the Japanese restaurant within the frame of a white Australia argue for the possibility of other forms of representation and identity being structured within the frame. Through the theoretical movement of the fold, I aimed to find an alternative to a unified, unchanging form of Japaneseness that locates an object and a subject in fixed positions. Framing the Japanese restaurant in the Australian context as a site of the fold thus allowed us to expose its constructedness and how the social apparatus functions to produce the new form of Japaneseness that can be sensed, rather than being essentialised, within exoticism. The fold metaphor provides a useful lens through which to demonstrate that the providers practices are structured within the frame of the domestic dominant (white) market, as well as informing it. Seeing their desire for the new form of Japaneseness through the theoretical lens also offers an effective way to understand why they absorb whiteness into their products and practices, while at the same time maintaining them as 'different', and how the ambivalent desire for a connection and a separation lies in the formation and operation of the Japanese restaurant in contemporary Australia. While this study concentrated only upon the incorporation of whiteness into Japaneseness, my ethnographic examples illustrated that Japaneseness can be re-worked through cross-cultural interactions, and hence the production of the new formation of representation can contain the possibility of positive agency for its subjects. 


\section{References}

Ang, I., 'The Curse of the Smile: Ambivalence and the "Asian” Woman in Australian Multiculturalism' Feminist Review, no. 52 (Spring 1996), pp. 36-49.

Appadurai, A., Modernity at Large: Cultural Dimensions of Globalization (Minneapolis and London: University of Minnesota Press, 1996).

__- 'Disjuncture and Difference in the Global Cultural Economy', Public Culture, vol. 2, no. 2 (1990), pp. 1-24.

Australian Bureau of Statistics 2006, '2006 Census Tables: Melbourne (Statistical Division)', Australian Bureau of Statistics. Retrieved 3 March 2008, from http://bit.ly/napJWZ .

Bestor, T. C., 'How Sushi Went Global', Foreign Policy, no. 212 (2000), pp. 54-63.

BhaBha, H., The Location of Culture (London and New York: Routledge, 1994).

Bourdieu, P., Distinction: A Social Critique of the Judgement of Taste, trans. Nice, R. (Cambridge, Massachusetts: Harvard University Press, 1984).

Clifford, J., The Predicament of Culture: Twentieth-Century Ethnography, Literature, and Art (Cambridge, Massachusetts: Harvard University Press, 1988).

Cook, I. and Crang, P., 'The World on a Plate: Culinary Culture, Displacement and Geographical Knowledge', Journal of Material Culture, vol. 1, no. 2 (1996), pp. 131-53.

Cwiertka, K. J., Modern Japanese Cuisine: Food, Power and National Identity (London: Reaktion Books, 2006).

Deleuze, G., The Fold: Leibniz and the Baroque, trans. Conley, T. (Minneapolis: University of Minnesota Press, 1993).

Douglas, M., 'Deciphering a Meal', Implicit Meanings: Essays in Anthropology (London and Boston: Routledge and Kegan Paul, 1975), pp. 231-51.

Dubecki, L., 'Espresso', The Age Online. Retrieved 30 September 2011, from http://www.theage.com.au/entertainment/restaurants-and-bars/espresso-20100217-o9pf.html.

Dyer, R., White (London and New York: Routledge, 1997).

Foucault, M., The Order of Things: An Archaeology of the Human Sciences (London and New York: Routledge, 1994).

Frost, W., Laing, J., Wheeler, F., and Reeves, K., 'Coffee Culture, Heritage and Destination Image: Melbourne and the Italian Model', in Jolliffe, L. (ed.), Coffee Culture, Destinations and Tourism (Bristol: Channel View Publications, 2010), pp. 99-110.

Hage, G., White Nation: Fantasies of White Supremacy in a Multicultural Society (Annandale, NSW: Pluto Press, 2000).

- - , 'At Home in the Entails of the West', in Grace, H. et al. (eds.), Home/World: Space, Community and Marginality in Sydney's West (Annandale, NSW: Pluto Press, 1997), pp. 99-153.

Hannerz, U., Transnational Connections: Culture, People and Places (London and New York: Routledge, 1996).

Ishige, N., The History and Culture of Japanese Food (London: Kegan Paul, 2001).

Ishige, N. et al. (eds.), Rosuanjerusu no Nihon Ryōriten: Sono Bunka Jinruigakuteki Kenkyū (Tōkyō: Domesu Shuppan, 1985). 
New Voices Volume 5

Korsmeyer, C., Making Sense of Taste: Food and Philosophy (Ithaca: Cornell University Press, 2002).

Lowe, L., Critical Terrains: French and British Orientalisms (Ithaca and London: Cornell University Press, 1991).

Mallos, T., 'Mediterranean Influences: Australia Moves From Damper To Focaccia', in Hutton, W. (ed.), The Food of Australia: Contemporary Recipes from Australia's Leading Chefs (Boston, MA: Periplus, 2000), pp. 16-18.

Morishita, K., Izakaya Raisan ['The Cult for Izakaya'] (Tokyo: Mainichi Shinbun Sha, 1992).

Ohnuki-Tierney, E., 'We Eat Each Other's Food to Nourish Our Body: The Global and the Local As Mutually Constituent Forces', in Grew, R. (ed.), Food in Global History (Boulder, CO: Westview Press, 1999), pp. $240-72$.

Robinson, M., Izakaya: The Japanese Pub and Cookbooks (Tokyo, New York and London: Kodansha International, 2008).

Said, E., Orientalism: Western Conceptions of the Orient (London: Penguin Books, 1991).

Stratton, J. and Ang, I., 'Multicultural Imagined Communities: Cultural Difference and National Identity in Australia and the USA', Continuum: The Australian Journal of Media \& Culture, vol. 8, no. 2 (1994), pp. 124-58.

Symons, M., The Shared Table: Ideas For Australian Cuisine (Office of Multicultural Affairs. Canberra: Australian Government Publishing Service, 1993).

Telstra Corporation Limited, 'Japanese Restaurants in VIC, Australia', The Yellow Pages Local Australian Business Directory Online. Retrieved 4 July 2011,

from http://www.yellowpages.com.au/search/listings?clue=japanese+restaurant\&locationClue=VIC\&x=59\&y=16.

Tobin, J. J., 'Introduction: Domesticating The West', in Tobin, J. J. (ed.), Re-Made in Japan: Everyday Life and Consumer Taste in a Changing Society (New Haven and London: Yale University Press, 1992), pp. 1-41.

Tobin, J., 'A Japanese-French Restaurant in Hawai'i', in Tobin, J. J. (ed.), Re-Made in Japan: Everyday Life and Consumer Taste in a Changing Society (New Haven and London: Yale University Press, 1992), pp. 159-75.

Turgeon, L. and Pastinelli, M., "Eat the World”: Postcolonial Encounters in Quebec City's Ethnic Restaurants', The Journal of American Folklore, vol. 115, no. 456 (Spring 2002), pp. 247-68.

Warde, A., 'Eating Globally: Cultural Flows and the Spread of Ethnic Restaurants', in Don, K. et al. (eds.), The Ends of Globalization (Oxford: Rowman and Littlefield Publishers, 2000), pp. 299-316.

Wilson, R. and Dirlik, A. (eds.), Asia/Pacific as Space of Cultural Production (Durham and London: Duke University Press, 1995).

Wilson, R. and Dissanayake, W. (eds.), Global/Local: Cultural Production and the Transnational Imaginary (Durham and London: Duke University Press, 1996).

Žižek, S., 'The Reality of the Virtual', Organs Without Bodies - Gilles Deleuze. Retrieved July 30 2011, from http://www.lacan.com/zizbenbrother.html. 